\title{
Partial island submergence and speciation in an adaptive radiation: a multilocus analysis of the Cuban green anoles
}

\author{
Richard E. Glor ${ }^{1 *}$, Matthew E. Gifford ${ }^{1}$, Allan Larson ${ }^{1}$, Jonathan B. Losos ${ }^{1}$, \\ Lourdes Rodríguez Schettino ${ }^{2}$, Ada R. Chamizo Lara ${ }^{2}$ and Todd R. Jackman \\ ${ }^{1}$ Department of Biology, Campus Box 1137, Washington University, St Louis, MO 63130-4899, USA \\ ${ }^{2}$ Instituto de Ecología y Sistemática, CITMA, Carretera de Varona km 3.5, Boyeros, La Habana 10800, \\ Apartado Postal 8029, Cuba \\ ${ }^{3}$ Department of Biology, Villanova University, Villanova, PA 19085, USA
}

\begin{abstract}
Sympatric speciation is often proposed to account for species-rich adaptive radiations within lakes or islands, where barriers to gene flow or dispersal may be lacking. However, allopatric speciation may also occur in such situations, especially when ranges are fragmented by fluctuating water levels. We test the hypothesis that Miocene fragmentation of Cuba into three palaeo-archipelagos accompanied species-level divergence in the adaptive radiation of West Indian Anolis lizards. Analysis of morphology, mitochondrial DNA (mt DNA) and nuclear DNA in the Cuban green anoles (carolinensis subgroup) strongly supports three predictions made by this hypothesis. First, three geographical sets of populations, whose ranges correspond with palaeo-archipelago boundaries, are distinct and warrant recognition as independent evolutionary lineages or species. Coalescence of nuclear sequence fragments sampled from these species and the large divergences observed between their mtDNA haplotypes suggest separation prior to the subsequent unification of Cuba ca. 5 Myr ago. Second, molecular phylogenetic relationships among these species reflect historical geographical relationships rather than morphological similarity. Third, all three species remain distinct despite extensive geographical contact subsequent to island unification, occasional hybridization and introgression of mtDNA haplotypes. Allopatric speciation initiated during partial island submergence may play an important role in speciation during the adaptive radiation of $A$ nolis lizards.
\end{abstract}

Keywords: adaptive radiation; speciation; introgression; hybridization; Anolis; Cuba

\section{INTRODUCTION}

Speciation is the least understood aspect of adaptive radiation (Schluter 2000). Classic models of allopatric divergence are often challenged by adaptive radiations occurring in small, geographically homogeneous areas where barriers to gene flow or dispersal may be lacking. In some such radiations, non-allopatric speciation is suggested: sympatric speciation, for example, is considered common in African rift-lake cichlids (Schliewen et al. 1994, 2001; Seehausen \& van Alphen 1999; Shaw et al. 2000). However, allopatric speciation also occurs in cichlids when large lakes become fragmented into smaller ones during historically dry periods (Sturmbauer \& Meyer 1992; Rüber et al. 1998; Sturmbauer et al. 2001). We test the hypothesis that a similar mechanism contributes to speciation in adaptive radiation of Anolis lizards.

West Indian anoles represent a classic example of a species-rich adaptive radiation within several relatively small, geographically isolated areas (Losos \& Schluter 2000). On Cuba, where anole diversity is highest, more than 60 species occur over an area of only $110000 \mathrm{~km}^{2}$ (Rodríguez-Schettino 1999). Most anole species on Cuba and other Greater Antillean islands result from within-island processes (Losos \& Schluter 2000), leading

*Author for correspondence (glor@biology.wustl.edu). some authors to suggest that sympatric speciation plays a part in anole diversification (Shaw et al. 2000; Thomas et al. 2003). However, several lines of evidence suggest that geographical processes play the dominant role in intraisland anole speciation.

Much of this evidence comes from small (area of less than $2000 \mathrm{~km}^{2}$ ) Lesser Antillean islands where anoles often exhibit extraordinarily high levels of geographical genetic structure (Malhotra \& Thorpe 1991, 1993, 1994, 1997a,b, 2000; Schneider 1996; Thorpe \& Malhotra 1996; Ogden \& Thorpe 2002; Stenson et al. 2002; Thorpe \& Stenson 2003). Although anole speciation is not known to have occurred on these small islands, probably owing to their small size (Losos \& Schluter 2000; Stenson et al. 2002), the same geographical processes acting there may result in speciation on the larger Greater Antillean islands (Stenson et al. 2002). Indeed, recent studies reveal high levels of mitochondrial DNA (mtDNA) geographical structure within several species of Greater Antillean anoles (Jackman et al. 2002; Glor et al. 2003). More generally, groups of closely related allopatrically or parapatrically distributed species, which are common on the large Greater Antillean islands, suggest an important role for geographical processes in intra-island anole speciation (Losos 1996).

One overlooked mechanism for allopatric differentiation in the Greater Antilles is partial submergence, or historical fragmentation of islands by over-water barriers (Stenson $e t$ 


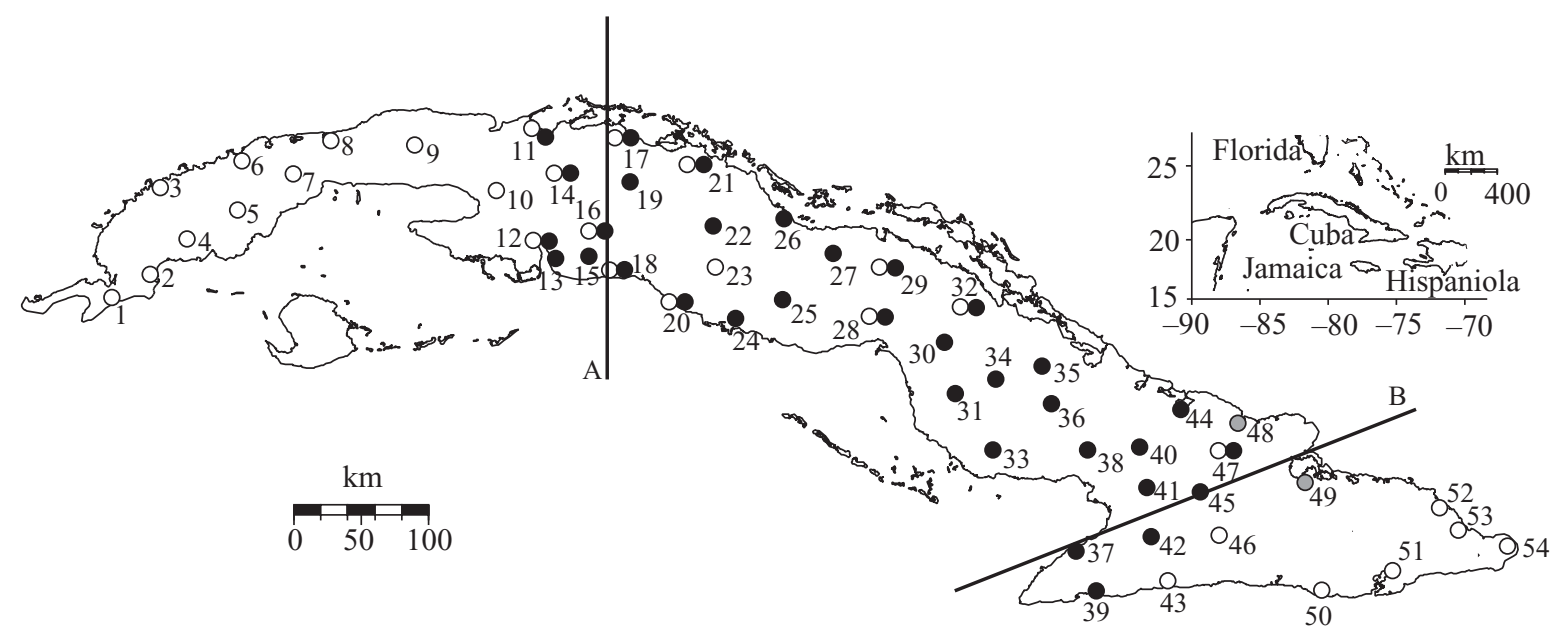

Figure 1. Sampling localities for populations included in this study. White, black and grey circles represent Anolis porcatus, $A$. allisoni and hybrid localities, respectively. Bold lines represent the Cárdenas-Cochinos (A) and Guacanayayabo-Nipe (B) fault lines marking borders between western, central, and eastern palaeo-archipelagos (MacPhee et al. 2003).

al. 2002), a pattern analogous to fragmentation of African rift lakes by lower water levels. Reconstructions of historically emergent areas of Cuba, for example, suggest that this island consisted of three distinct archipelagos separated by deepwater channels throughout much of the Cenozoic before being permanently united in the Pliocene (IturraldeVinent \& MacPhee 1999; MacPhee et al. 2003; Graham 2003). Evidence for fragmentation of Cuba during the Miocene is compelling and includes the discovery of fossil marine vertebrates in central Cuba (MacPhee et al. 2003). Several lines of evidence also suggest that the Miocene was an important period of Anolis diversification: ecologically specialized anoles occur in Early to Mid-Miocene Dominican amber (de Queiroz et al. 1998) and molecular analyses of albumin, allozymes and mtDNA suggest that anoles arrived in the West Indies 16-37 Myr ago and that most species diverged more than 10 Myr ago (Hedges 1996; Jackman et al. 2002; Glor et al. 2003).

We test the hypothesis that partial submergence of Cuba contributed to speciation of the canopy-dwelling green anoles (carolinensis subgroup). This subgroup includes three morphologically distinct populations whose distributions closely mirror the boundaries of the palaeo-archipelagos (figure 1). Anolis allisoni, a large species whose males have striking blue heads, is common across the area corresponding to the large central palaeo-archipelago. Anolis porcatus, which has a smaller body size, includes two geographically disjunct and morphologically distinct populations (Ruibal \& Williams 1961) whose ranges correspond to the eastern and western palaeo-archipelagos (figure 1). Anolis porcatus also extends into Central Cuba but is rare where its range overlaps with the larger $A$. allisoni (Ruibal \& Williams 1961; Rodríguez-Schettino 1999). Character displacement in body size observed in $A$. porcatus suggests that interspecific competition may explain this pattern (Schoener 1977).

The partial submergence hypothesis makes three specific predictions. First, all three morphologically distinguishable populations (eastern and western $A$. porcatus and $A$. allisoni) should represent distinct evolutionary lineages that diverged prior to the unification of Cuba in the Pliocene. Second, phylogenetic relationships among these populations should reflect historical geographical relationships rather than morphology: specifically, the centrally distributed $A$. allisoni should render $A$. porcatus paraphyletic. Third, all three populations should remain morphologically and genetically distinct despite longstanding geographical contact, a prediction challenged by the occurrence of hybrid individuals in eastern Cuba (Ruibal \& Williams 1961; Schwartz \& Thomas 1975).

We test these predictions through comprehensive geographical sampling and a combined analysis of morphology, mtDNA, and nuclear (nDNA) sequence data. The use of multiple independent markers can provide robust lineage diagnoses and reveal genetic interactions among lineages upon contact. MtDNA is an ideal marker for lineage diagnosis (Wiens \& Penkrot 2002) because isolated populations should achieve reciprocal monophyly more rapidly for mtDNA than nDNA due to the smaller effective population size of mtDNA under ideal conditions (Moore 1995; but see Hoelzer 1997). However, mtDNA is prone to introgression, or lateral transfer across species boundaries (e.g. Gyllensten \& Wilson 1987; Tegelström 1987; Good et al. 2003); therefore, lineage diagnoses are strongest when confirmed by nDNA variation or morphology (Wiens \& Penkrot 2002; Morando et al. 2003).

A multilocus approach is also required to elucidate genetic interactions between lineages where they make contact. Comparisons of mitochondrial and nuclear markers permit tests of the mechanisms that underlie concordant or discordant patterns of variation. Discordance between $\mathrm{mtDNA} /$ morphology and $\mathrm{nDNA}$ is expected among recently diverged groups that retain ancestral polymorphisms for nuclear genes (i.e. incomplete lineage sorting). Discordance between $\mathrm{nDNA} /$ morphology and mtDNA meanwhile is expected when introgression produces lateral transfer of genes between divergent populations (e.g. Gyllensten \& Wilson 1987; Tegelström 1987; Good et al. 2003). Introgression is also distinguished from incomplete lineage sorting by its characteristic geographical signal, with introgressed haplotypes being most common where the ranges of distinct populations abut one another (Harrison \& Bogdanowicz 1997; Goodman et al. 1999; García-París et al. 2003). 


\section{MATERIAL AND METHODS}

\section{(a) Specimens examined and species identification}

We classified 309 individuals from 54 Cuban localities as $A$. allisoni, $A$. porcatus or a hybrid of these two species based on three characters: body coloration, height of the canthal ridge (a sharply defined ridge running from the eye to the tip of the snout) and shape of the ear opening (Ruibal \& Williams 1961). Male $A$. allison $i$ have a distinct blue anterior whereas female $A$. allison $i$ and both sexes of $A$. porcatus are uniformly green (but see Pérez-Beato \& Alvarez 1986). Male $A$. allisoni are also distinguished by raised canthal ridges that obscure the frontal ridge when viewed laterally (Ruibal \& Williams 1961). Finally, the shape of the ear opening distinguishes both sexes of $A$. allisoni from $A$. porcatus: Anolis allisoni have a distinct elongate opening with a shallow posterior depression, whereas $A$. porcatus have simple cylindrical ear openings (see figures in Ruibal \& Williams 1961; Stafford \& Meyer 1999). Hybrids from the region of species overlap were identified by intermediately shaped ear openings or a conflict of species diagnosis among the three characters examined. Species diagnoses were made at time of capture and independently confirmed by at least two observers.

\section{(b) Molecular methods}

The nuclear gene encoding the visual pigment rhodopsin is useful for phylogenetic analyses (Bossuyt \& Milinkovitch 2000; Page 2000; Birks \& Edwards 2002; Chen et al. 2003; Veith et al. 2003) and occurs as a single copy in $A$. carolinensis, a close relative of $A$. porcatus and $A$. allisoni (Kawamura \& Yokoyama 1994). Here, we examine the third intron and portions of the flanking exon sequence for this gene. We also examine a $1200 \mathrm{bp}$ fragment of mtDNA that includes complete sequence for ND2 and tRNA ${ }^{\text {Trp }}$ and partial sequence for $\mathrm{tRNA}^{\mathrm{Ala}}$. Additional details of our molecular protocols are given in electronic Appendix A.

\section{(c) Phylogenetic analyses}

We constructed phylogenetic trees independently for each molecular dataset using maximum-parsimony and Bayesian criteria. Each analysis included five outgroup taxa selected on the basis of previous phylogenetic analyses (Burnell \& Hedges 1990; Jackman et al. 1999; Nicholson et al. 2004): A. altitudinalis, $A$. isolepis, $A$. oporinus, $A$. alutaceus and $A$. loysiana. PAUP v.4.0b10 (Swofford 2002) generated phylogenetic trees under maximum parsimony using 100 heuristic searches with TBR branch swapping and 10 random sequence-addition replicates. Parsimony analyses included only a single individual from each population to facilitate computational efficiency. One thousand bootstrap replicates with 10 random additions per replicate and decay indices ('branch support' of Bremer (1994)) measured support for individual nodes. Following model selection using MRMODELTEST v.1.1b (available from http://www.ebc.uu.se/systzoo/staff/nylander.html) Bayesian analyses were implemented in MRBAYES v.3.04 (Huelsenbeck \& Ronquist 2001) by running four chains for $1 \times 10^{6}$ generations, sampling every 10000 generations, and repeating this search five times. Posterior-probability values indicate support for all nodes.

\section{RESULTS}

Morphological characters diagnose $124 \mathrm{~A}$. porcatus from 31 localities, $172 \mathrm{~A}$. allisoni from 34 localities and 13 hybrids from two localities (figure 1). Electronic Appendix B lists specimen voucher, locality and GenBank accession numbers.

Electrophoresis of rhodopsin PCR fragments from $84 \mathrm{~A}$. allisoni, $66 \mathrm{~A}$. porcatus and 10 hybrids on standard $2 \%$ agarose gels identifies three distinct fragment lengths. The longest (ca. $1400 \mathrm{bp}$ ) and shortest (ca. $900 \mathrm{bp}$ ) fragments, hereafter called 'long' and 'short', are common. Sequencing reveals that the long fragment results from a $471 \mathrm{bp}$ insertion in the intron. The intermediate fragment ( $c a$. $1200 \mathrm{bp}$ ) contains a $326 \mathrm{bp}$ insertion unique to a single individual of $A$. porcatus (GLOR3045), which also contains the short fragment. We report rhodopsin sequences from 73 individuals representing five outgroup taxa, $32 \mathrm{~A}$. allisoni from 17 localities, $27 \mathrm{~A}$. porcatus from 16 localities and nine hybrids from two localities. Sequences from fragments of two sizes are reported from three $A$. porcatus and three hybrids, producing a total of 79 sequences, which form an aligned dataset of $1697 \mathrm{bp}$, including both large inserts.

Bayesian analysis of 58 unique sequences using the GTR $+\mathrm{I}+\Gamma$ model produces a strict consensus tree with mean ln-likelihood of -3666.62 (s.d. $=10.34$ ) following a 'burn in' of 30000 generations (figure 2). Parsimony analysis of 95 informative characters limited to $1 \times 10^{6}$ rearrangements (by which point the analysis reaches a stable tree length) for each of 10 addition replicates produces more than $1 \times 10^{5}$ trees of 199 steps. Because Bayesian and maximum-parsimony haplotype phylogenies are highly congruent, only the Bayesian tree is presented here with support values from maximum parsimony included for shared branches (figure 2).

One hundred and seventy-seven new mitochondrial DNA sequences representing $95 \mathrm{~A}$. allisoni, $69 \mathrm{~A}$. porcatus and 10 hybrids plus previously published outgroup sequences (Jackman et al. 1999) obtained from GenBank form an aligned dataset of 1172 sites. Twenty-nine redundant sequences are excluded from phylogenetic analyses. Bayesian analysis under the GTR $+\mathrm{I}+\Gamma$ model produces a well-resolved strict consensus tree with a mean ln-likelihood of -12343.28 (s.d. $=69.23$ ) following a 'burn in' of 80000 generations (figure 3). Parsimony analysis of 409 informative characters finds six most-parsimonious trees of 1619 steps, which are largely congruent with the Bayesian topology (figure 3).

Rhodopsin and mtDNA sequence data produce well-supported and highly congruent topologies. Both markers recover three major subclades of haplotypes from $A$. allisoni and $A$. porcatus (figures 2 and 3 ). For rhodopsin, these subclades correspond closely with morphology and delimit $A$. allisoni and eastern and western populations of $A$. porcatus (figure 2). PCR amplification for unsequenced samples confirms the distinction of $A$. allisoni from $A$. porcatus by revealing a strong association of long and short fragments with the $A$. allisoni and $A$. porcatus phenotypes, respectively $\left(\chi^{2}=136.07, p<0.0001\right)$. Only five individuals violate this association: two $A$. porcatus from locality 12 (one with only the long fragment and one with both long and short fragments), one $A$. porcatus from locality 51 that has both the long and short fragments, and single individuals of $A$. allisoni from localities 16 and 39 that contain only the long fragment (figure 4). Five out of 10 morphologically hybrid individuals contain both the long and short fragments.

MtDNA haplotype structure and morphology exhibit more discordance than observed between rhodopsin and morphology (table 1; figures 3 and 4). Nevertheless, three contingency-table tests reveal a significant association 


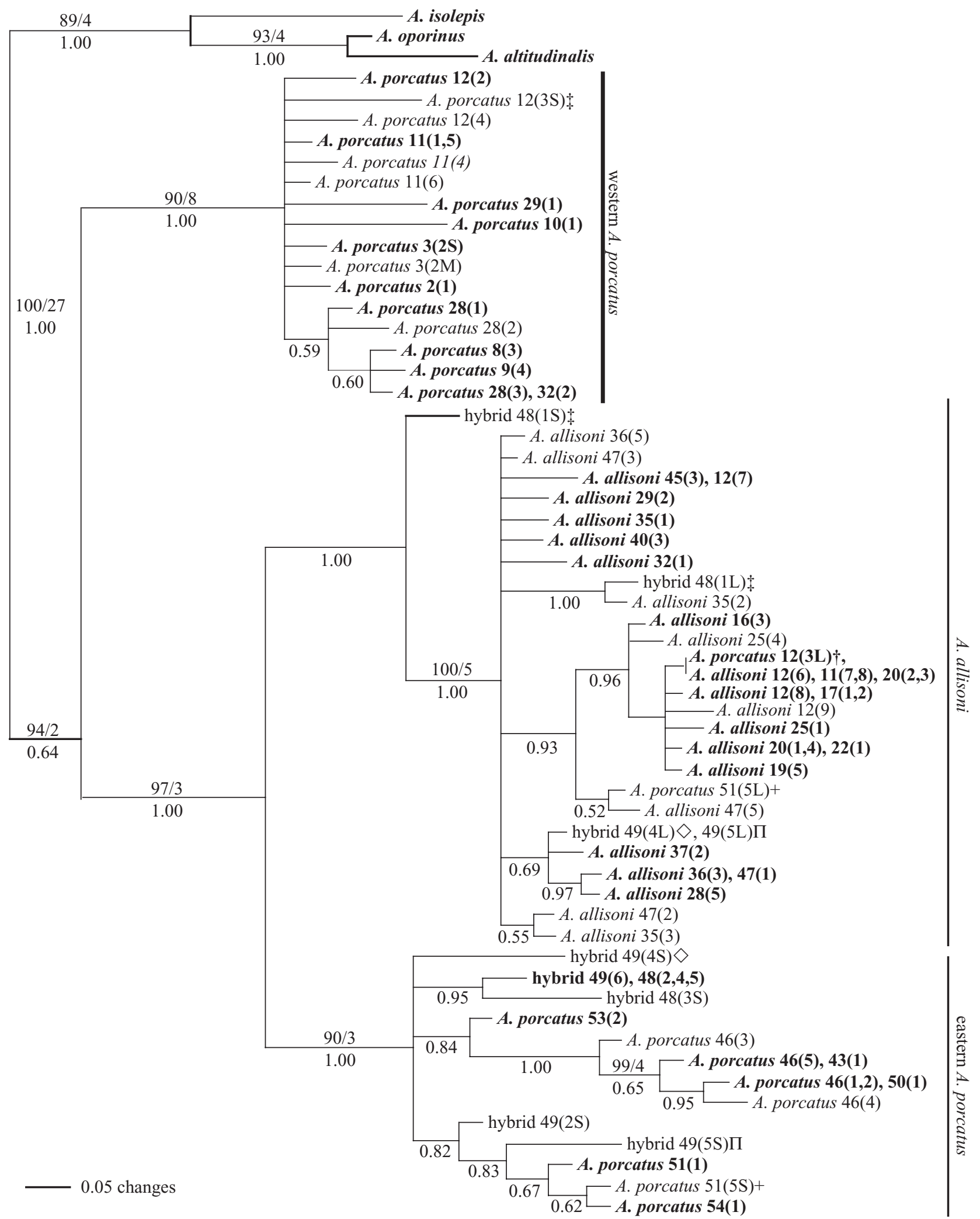

Figure 2. Majority-rule consensus of 485 post burn-in trees from Bayesian analysis of rhodopsin gene sequences, with branch lengths proportional to number of changes. Taxon labels indicate morphological species diagnosis, locality number and specimen number. $\mathrm{L}, \mathrm{M}$ or $\mathrm{S}$ following a specimen number indicate the long, intermediate and short fragment lengths, respectively. Taxa in bold are included in the parsimony analysis. Two outgroups (Anolis alutaceus and A. loysiana) are pruned from this tree. Numbers above nodes represent bootstrap/decay values from maximum-parsimony analyses; numbers below nodes represent posteriorprobability values from Bayesian analysis. Sequences of different fragments from the same individual are indicated with symbols.

between the three major mtDNA clades, which differ by Tamura-Nei corrected distances exceeding 0.098, and each of the three morphologically distinct populations.
These tests reveal associations between mtDNA haplotype-clade status and morphology for all individuals sampled $\left(\chi^{2}=63.04, p<0.0001\right)$, individuals sampled from 


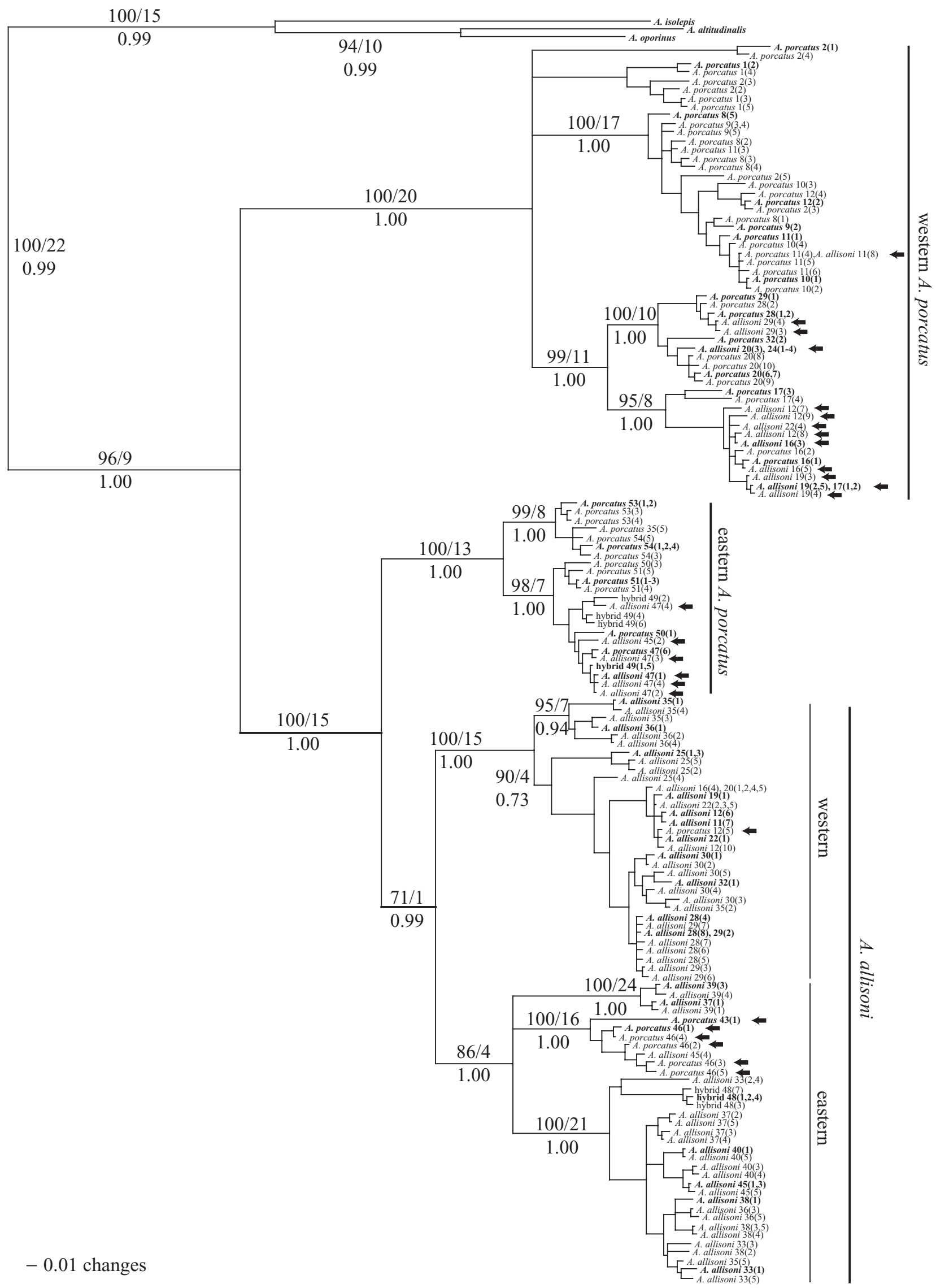

Figure 3. Majority-rule consensus of 460 post burn-in trees from Bayesian analysis of mtDNA sequences, with branch lengths proportional to number of changes. Taxon labels indicate morphological species diagnosis, locality number, and specimen number. Taxa in bold are included in the parsimony analysis. Two outgroup taxa (Anolis alutaceus and $A$. loysiana) are pruned from this tree. Numbers above nodes represent bootstrap/decay values from maximum-parsimony analyses; numbers below nodes represent posterior probability values from Bayesian analysis. Arrows denote introgressed haplotypes. 


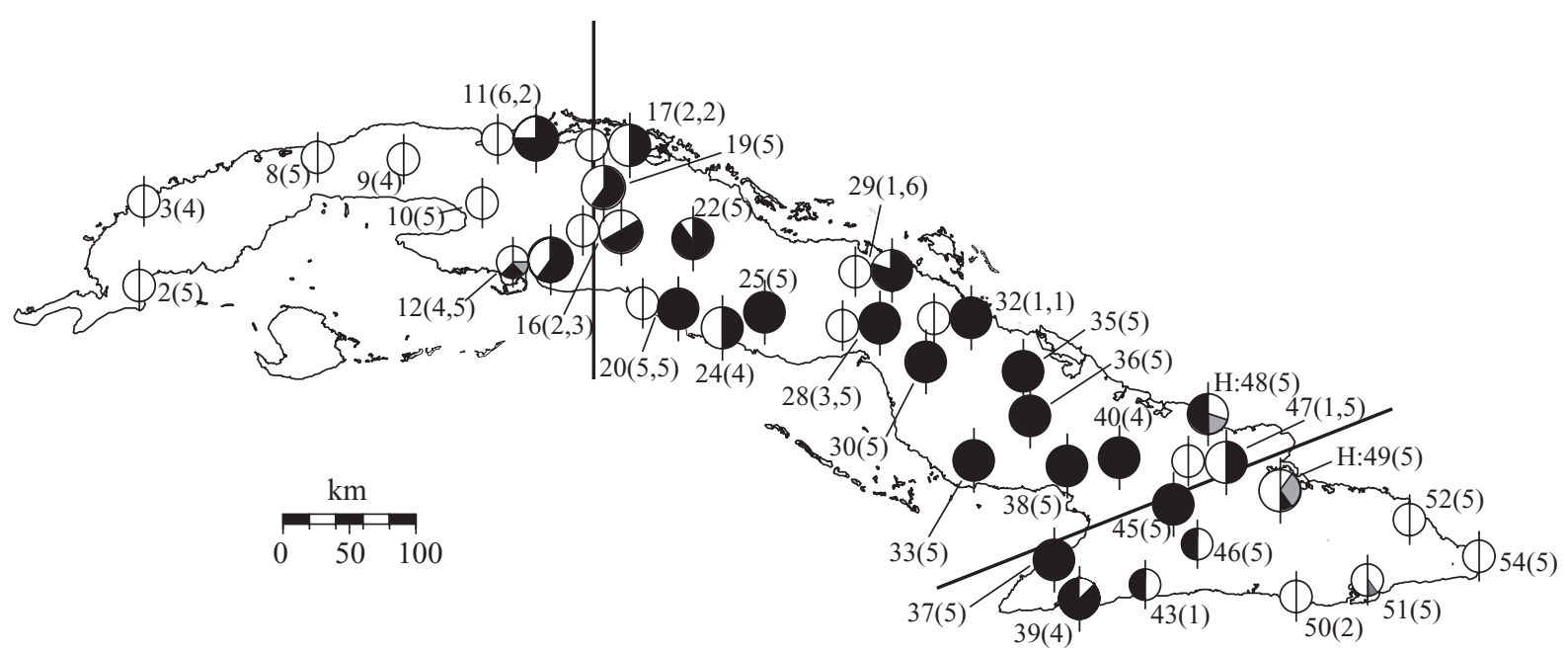

Figure 4. Distribution of phenotypes, mtDNA haplotypes and rhodopsin-gene fragment sizes. Larger circles denote populations morphologically diagnosed as Anolis allisoni and two hybrid populations (indicated by ' $\mathrm{H}:$ '); smaller circles denote populations morphologically diagnosed as $A$. porcatus. Each circle is split with the right half showing the frequency of rhodopsin fragment lengths and the left half showing the frequency of mtDNA haplotypes. Black fill indicates the proportion of individuals with mtDNA haplotypes or rhodopsin-gene fragments associated with $A$. allisoni, and white fill indicates the proportion of individuals with markers associated with $A$. porcatus. Grey fill indicates the proportion of individuals with both the long and short rhodopsin fragments. As in figure 1, bold lines indicate boundaries of western, central and eastern palaeo-archipelagos. Sample sizes for each locality are shown in parentheses; where both species are sampled from a given locality, the sample size of $A$. porcatus appears first.

only the area where the ranges of $A$. allisoni and $A$. porcatus overlap $\left(\chi^{2}=33.60, p<0.0001\right)$, and individuals from localities where both species were collected sympatrically $\left(\chi^{2}=16.17, p<0.0001\right)$ (table 1$)$; the second and third of these analyses test whether associations persist in sympatry and reject the hypothesis that associations between haplotype clade and phenotype are artefacts of geography. Discordance between morphology and mtDNA is strongest where $A$. allisoni and $A$. porcatus make contact in eastern and western Cuba (figure 4).

Both markers reveal that haplotypes of $A$. porcatus form a paraphyletic group with respect to sequences from $A$. allisoni (figures 2 and 3 ). Meanwhile, sequences from hybrid individuals occur in the eastern $A$. porcatus and $A$. allisoni clades. Heterozygous individuals for both the long and short fragments of rhodopsin yield sequences that group with $A$. allisoni and $A$. porcatus, respectively.

\section{DISCUSSION}

Several lines of evidence support the first prediction of the partial-submergence hypothesis by revealing that each of the three populations whose distributions correspond with palaeo-archipelago boundaries represents a separate evolutionary lineage. First, morphological analysis of more than 300 specimens confirms that the two previously recognized species ( $A$. allisoni and $A$. porcatus) are distinct and that interspecific hybridization is rare (figure 1 ). This result is corroborated by molecular analyses of mtDNA and nDNA, which suggest that $A$. allisoni and $A$. porcatus are phylogenetically distinct (figures 2 and 3 ), distinguished by a $471 \mathrm{bp}$ insert in the rhodopsin intron of $A$. allisoni, and that the genetic consequences of interspecific hybridization are limited primarily to mtDNA introgression (see below).

Eastern and western populations of $A$. porcatus are also phylogenetically distinct and deeply divergent (figures 2 and 3), supporting the hypothesis of Ruibal \& Williams (1961) that these morphologically distinct populations warrant status as distinct species. Furthermore, our sampling confirms that these populations are geographically isolated by a distributional gap in eastern Cuba (Ruibal \& Williams 1961; figure 1), strengthening the hypothesis that they represent independently evolving evolutionary lineages. Although our results clearly support species-level status for eastern and western populations of $A$. porcatus, a formal elevation of these populations is beyond the scope of this report.

Two lines of evidence suggest that divergence among all three lineages discussed above ( $A$. allisoni and eastern and western $A$. porcatus) is ancient and occurred prior to the unification of Cuba in the Pliocene. First, all three lineages show nearly complete reciprocal monophyly for nDNA sequences. Such monophyly is unlikely for nuclear-based markers in recently separated populations, particularly when inbreeding effective sizes are large (Hare et al. 2002). Although the occurrence of a bottleneck may have accelerated coalescence, the current abundance and genetic diversity of $A$. porcatus and $A$. allisoni suggest extremely large inbreeding effective sizes. Moreover, Tamura-Nei corrected divergences among mtDNA haplotypes from all three species exceed $9.8 \%$. Based on a calibration of $1.3 \%$ pairwise divergence per million years for a similar gene region in other iguanian lizards (Macey et al. 1998), this result suggests more than $7 \mathrm{Myr}$ of evolutionary separation among lineages and places their divergence in the Miocene.

The second prediction of the partial submergence hypothesis, that phylogenetic relationships among populations should reflect historical geographical relationships rather than morphology, is confirmed by both nuclear and mitochondrial genomic markers. In particular, both markers find that the centrally distributed $A$. allisoni renders $A$. porcatus paraphyletic (figures 2 and 3 ). The observed pattern suggests that divergence occurred 
Table 1. mtDNA haplotype clade and phenotype.

(Column labels indicate geographical haplotype clades: W, western; C, central; E, eastern. For Anolis allisoni and A. porcatus, numbers are provided for three situations: the entire range of the species (entire range), only the region where the two species' ranges overlap (overlapping ranges), and only localities where the two species were found sympatrically during the study (sympatry).)

\begin{tabular}{llcccc}
\hline & W & C & E & total \\
\hline A. allisoni & entire range & 20 & 69 & 6 & 95 \\
& overlapping ranges & 20 & 69 & 6 & 95 \\
sympatry & 11 & 17 & 0 & 28 \\
A. porcatus & entire range & 44 & 7 & 18 & 69 \\
& overlapping ranges & 26 & 7 & 0 & 34 \\
hybrid & sympatry & 20 & 5 & 5 & 21 \\
\hline
\end{tabular}

initially between western $A$. porcatus and $A$. allisonil eastern $A$. porcatus followed by divergence between the latter two populations.

The partial-submergence hypothesis suggests that the three species identified above have had geographical contact since the late Miocene or early Pliocene. To remain genetically distinct over this interval, interspecific hybridization must be limited. Hybridization among anole species in nature is rare, but $A$. allisoni and $A$. porcatus represent one of six potential instances identified in a recent review (Losos 2004). Our study is the first detailed examination of hybridization's genetic consequences in anoles and suggests that while interspecific hybridization occurs among species of Cuban green anoles, it is restricted to narrow hybrid zones along the edges of $A$. allisoni's range (figure 4).

Morphologically identifiable hybrids between $A$. allisoni and $A$. porcatus are restricted to two populations that flank the boundary between the central and eastern palaeo-archipelagos in eastern Cuba (figures 1 and 4). This is the same region where hybrids were noted previously (Ruibal \& Williams 1961; Schwartz \& Thomas 1975), suggesting that this hybrid zone has been stable for at least four decades.

Molecular analysis of the rhodopsin intron further suggests that hybridization is limited to narrow contact zones along the eastern and western edges of $A$. allisoni's range. Only seven out of the 174 individuals screened for length variation in rhodopsin are heterozygotes containing fragments typical of both $A$. porcatus and $A$. allisoni, and five of these are also morphologically identified as hybrids (figure 4). The two remaining heterozygotes were morphologically identified as $A$. porcatus, one from a locality where $A$. allisoni and $A$. porcatus occur sympatrically in western Cuba (locality 12) and one from a locality outside the range of $A$. allisoni in eastern Cuba (locality 51) (figure 4). The first individual, considered in light of our mtDNA analysis (see next paragraph), suggests that morphologically undetectable hybridization has occurred in western Cuba. The second individual suggests incomplete lineage sorting or limited introgression of nuclear markers from $A$. allisoni into the eastern population of $A$. porcatus.

Interspecific hybridization appears to have had a major impact on the distribution of mtDNA variation. Discordance between mtDNA haplotype clades and morphology occurs in 33 individuals from 11 localities (table 1; figure 4). The geographical pattern of this discordance combined with the strong concordance between rhodopsin sequences and morphology suggest mtDNA introgression between distinct evolutionary lineages. Introgressed mtDNA haplotypes are most common along the edges of $A$. allisoni's range in eastern and western Cuba. Introgression of $A$. porcatus haplotypes into $A$. allisoni occurs primarily in western Cuba: the five westernmost populations of $A$. allison $i$ all contain introgressed haplotypes whereas the seven populations farthest from the western contact zone contain no introgressed haplotypes (figure 4). Meanwhile, introgression of $A$. allisoni haplotypes into $A$. porcatus occurs primarily in eastern Cuba, where two populations of $A$. porcatus contain only $A$. allisoni haplotypes (figure 4 ). This type of geographically structured discordance is not expected when the retention of ancestral polymorphisms is the underlying cause (Harrison \& Bogdanowicz 1997; García-París et al. 2003). Moreover, ancestral polymorphisms are expected to persist for longer in nDNA than mtDNA (Moore 1995), which is the reverse of the pattern observed in Cuban green anoles. Our results are consistent with hypotheses that limited hybridization at geographical borders of species is sufficient for considerable transspecific introgression of mitochondrial haplotypes (Gyllensten \& Wilson 1987; Goodman et al. 1999).

\section{CONCLUSIONS}

Variation in morphology, the nuclear rhodopsin gene and mtDNA supports three predictions of the hypothesis that partial submergence of Cuba during the Miocene initiated speciation among populations of Cuban green anoles. Despite the limited geographical range of Cuban green anoles, historical barriers to gene exchange separated lineages that have maintained their evolutionary distinctness through long periods of evolutionary time, and despite some genetic interactions. If this pattern is general, accumulation of allopatric or parapatric speciation over many millions of years of evolutionary history has probably been important for Anolis species diversification, and sympatric speciational processes are not required to explain the group's high species richness. The generality of this hypothesis should be tested using other taxa from Cuba and other Greater Antillean islands. These other islands have probably experienced similar histories of emergence and partial submergence. For example, portions of the Valle de Neiba on Hispaniola were regularly inundated, dividing this island into two isolated segments long considered important biogeographic units (Powell et al. 1999). 
A recent study suggests that this recurring partial submersion influences the distribution of genetic variation among populations of the teiid lizard Ameiva chrysolaema (Gifford et al. 2004).

The authors thank J. Kolbe, S. Poe, R. Mueller, V. Rivalta González and A. Torres Barboza for field assistance. Lukas Rüber and an anonymous reviewer provided constructive criticisms. Financial support provided by a National Science Foundation (NSF) grants DEB9982736 and DEB0206710 and an NSF pre-doctoral fellowship to R.E.G.

\section{REFERENCES}

Birks, S. M. \& Edwards, S. V. 2002 A phylogeny of the megapodes (Aves: Megapodiidae) based on nuclear and mitochondrial DNA sequences. Mol. Phylogenet. Evol. 23, 408-421.

Bossuyt, F. \& Milinkovitch, M. C. 2000 Convergent adaptive radiations in Madagascan and Asian ranid frogs reveal covariation between larval and adult traits. Proc. Natl Acad. Sci. USA 97, 6585-6590.

Bremer, K. 1994 Branch support and tree stability. Cladistics 10, 295-304.

Burnell, K. L. \& Hedges, S. B. 1990 Relationships of West Indian Anolis (Sauria: Iguanidae): an approach using slowevolving protein loci. Carib. F. Sci. 26, 7-30.

Chen, W. J., Bonillo, C. \& Lecointre, G. 2003 Repeatability of clades as a criterion of reliability: a case study for molecular phylogeny of Acanthomorpha (Teleostei) with larger number of taxa. Mol. Phylogenet. Evol. 26, 262-288.

de Queiroz, K., Chu, L.-R. \& Losos, J. B. 1998 A second Anolis lizard in Dominican amber and the systematics and ecological morphology of Dominican amber anoles. Am. Mus. Novitates 3249, 1-22.

García-París, M., Alcobendas, M., Buckley, D. \& Wake, D. B. 2003 Dispersal of viviparity across contact zones in Iberian populations of fire salamanders (Salamandra) inferred from discordance of genetic and morphological traits. Evolution 57, 129-143.

Gifford, M. E., Powell, R., Larson A. \& Gutberlet Jr, R. L. 2004 Population structure and history of a phenotypically variable teiid lizard (Ameiva chrysolaema) from Hispaniola: the influence of a geologically complex island. Mol. Phylogenet. Evol. 32, 735-748.

Glor, R. E., Kolbe, J. K., Powell, R., Larson, A. \& Losos, J. B. 2003 Phylogenetic analysis of ecological and morphological diversification in Hispaniolan trunk-ground anoles (Anolis cybotes group). Evolution 57, 2383-2397.

Good, J. M., Demboski, J. R., Nagorsen, D. W. \& Sullivan, J. 2003 Phylogeography and introgressive hybridization: chipmunks (genus Tamias) in the northern Rocky Mountains. Evolution 57, 1900-1916.

Goodman, S. J., Barton, N. H., Swanson, G., Abernethy, K. \& Pemberton, J. M. 1999 Introgression through rare hybridization: a genetic study of a hybrid zone between red and sika deer (genus Cervus) in Argyll, Scotland. Genetics 152, 355-371.

Graham, A. 2003 Geohistory models and Cenozoic paleoenvironments of the Caribbean region. Syst. Bot. 28, 378-386.

Gyllensten, U. \& Wilson, A. C. 1987 Interspecific mitochondrial DNA transfer and the colonization of Scandinavia by mice. Genet. Res. 49, 25-29.

Hare, M. P., Cipriano, F. \& Palumbi, S. R. 2002 Genetic evidence on the demography of speciation in allopatric dolphin species. Evolution 56, 804-816.

Harrison, R. G. \& Bogdanowicz, S. M. 1997 Patterns of variation and linkage disequilibrium in a field cricket hybrid zone. Evolution 51, 493-505.
Hedges, S. B. 1996 The origin of West Indian amphibians and reptiles. In Contributions to West Indian herpetology: a tribute to Albert Schwartz vol. 12 (ed. R. Powell \& R. W. Henderson), pp. 95-128. Ithaca, NY: Society for the Study of Amphibians and Reptiles.

Hoelzer, G. A. 1997 Inferring phylogenies from mtDNA variation: mitochondrial-gene trees versus nuclear-gene trees revisited. Evolution 51, 622-626.

Huelsenbeck, J. P. \& Ronquist, F. 2001 MrBayes: Bayesian inference of phylogenetic trees. Bioinformatics 17, 754755 .

Iturralde-Vinent, M. A. \& MacPhee, R. D. E. 1999 Paleogeography of the Caribbean region: implications for Cenozoic biogeography. Bull. Am. Mus. Nat. Hist. 238, 1-95.

Jackman, T. R., Larson, A., de Queiroz, K. \& Losos, J. B. 1999 Phylogenetic relationships and tempo of early diversification in Anolis lizards. Syst. Biol. 48, 254-285.

Jackman, T. R., Irschick, D. J., de Queiroz, K., Losos, J. B. \& Larson, A. 2002 A molecular phylogenetic perspective on evolution of the lizards of the Anolis grahami series. F. Exp. Zool. 294, 1-16.

Kawamura, S. \& Yokoyama, S. 1994 Cloning of the rhodopsin-encoding gene from the rod-less lizard Anolis carolinensis. Gene 149, 267-270.

Losos, J. B. 1996 Ecological and evolutionary determinants of the species-area relation in Caribbean anoline lizards. Phil. Trans. R. Soc. Lond. B 351, 847-854.

Losos, J. B. 2004 Adaptation and speciation in Caribbean Anolis lizards. In Adaptive speciation (ed. U. Dieckmann, M. Doebeli, J. A. J. Metz, \& D. Tautz). Cambridge University Press. (In the press.)

Losos, J. B. \& Schluter, D. 2000 Analysis of an evolutionary species-area relationship. Nature 408, 847-850.

Macey, J. R., Schulte, J. A., Ananjeva, N. B., Larson, A., Rastegar-Pouyani, N., Shammakov, S. M. \& Papenfuss, T. J. 1998 Phylogenetic relationships among agamid lizards of the Laudakia caucasia species group: testing hypotheses of biogeographic fragmentation and an area cladogram for the Iranian Plateau. Mol. Phylogenet. Evol. 10, 118-131.

MacPhee, R. D. E., Iturralde-Vinent, M. A. \& Gaffney, E. S. 2003 Domo de Zaza, an early Miocene vertebrate locality in south-central Cuba, with notes on the tectonic evolution of Puerto Rico and the Mona Passage. Am. Mus. Novitates 3394, 1-42.

Malhotra, A. \& Thorpe, R. S. 1991 Microgeographic variation in Anolis oculatus, on the island of Dominica, West Indies. F. Evol. Biol. 4, 321-335.

Malhotra, A. \& Thorpe, R. S. 1993 An experimental fieldstudy of a eurytopic anole, Anolis oculatus. F. Zool. 229, 163170.

Malhotra, A. \& Thorpe, R. S. 1994 Parallels between island lizards suggests selection on mitochondrial-DNA and morphology. Proc. R. Soc. Lond. B 257, 37-42.

Malhotra, A. \& Thorpe, R. S. 1997 a Microgeographic variation in scalation of Anolis oculatus (Dominica, West Indies): a multivariate analysis. Herpetologica 53, 49-62.

Malhotra, A. \& Thorpe, R. S. $1997 b$ Size and shape variation in a Lesser Antillean anole, Anolis oculatus (Sauria: Iguanidae) in relation to habitat. Biol. F. Linn. Soc. 60, 53-72.

Malhotra, A. \& Thorpe, R. S. 2000 The dynamics of natural selection and vicariance in the Dominican anole: patterns of within-island molecular and morphological divergence. Evolution 54, 245-258.

Moore, W. S. 1995 Inferring phylogenies from mtDNA variation: mitochondrial-gene trees versus nuclear-gene trees. Evolution 49, 718-726. 
Morando, M., Avila, L. J. \& Sites, J. W. 2003 Sampling strategies for delimiting species: genes, individuals, and populations in the Liolaemus elongatus-kriegi complex (Squamata: Liolaemidae) in Andean-Patagonian South America. Syst. Biol. 52, 159-185.

Nicholson, K. E., Glor, R. E., Kolbe, J. K., Larson, A., Hedges, S. B. \& Losos, J. B. 2004 Mainland colonization by an island species. F. Biogeogr. (In the press.)

Ogden, R. \& Thorpe, R. S. 2002 Molecular evidence for ecological speciation in tropical habitats. Proc. Natl Acad. Sci. USA 99, 13 612-13615.

Page, R. D. M. 2000 Extracting species trees from complex gene trees: reconciled trees and vertebrate phylogeny. Mol. Phylogenet. Evol. 14, 89-106.

Pérez-Beato, O. \& Alvarez, B. 1986 Límites de variación de la coloración en Anolis allinsoni: hibridación o polimorfismo? Poeyana 327, 1-5.

Powell, R., Ottenwalder, J. A. \& Inchaustegui, S. J. 1999 The Hispaniolan herpetofauna: diversity, endemism, and historical perspectives, with comments on Navassa Island. In Caribbean amphibians and reptiles (ed. B. I. Crother), pp. 93168. San Diego, CA: Academic.

Rodríguez-Schettino, L. 1999 The iguanid lizards of Cuba. Gainesville, FL: The University of Florida Press.

Rüber, L., Verheyen, E., Sturmbauer, C. \& Meyer, A. 1998 Lake level fluctuations and speciation in rock-dwelling cichlid fish in Lake Tanganyika, East Africa. In Evolution on islands (ed. P. R. Grant), pp. 225-240. Oxford University Press.

Ruibal, R. \& Williams, E. E. 1961 Two sympatric Cuban anoles of the carolinensis group. Bull. Mus. Comp. Zool. 125, 183-208.

Schliewen, U., Rassmann, K., Markmann, M., Markert, J., Kocher, T. \& Tautz, D. 2001 Genetic and ecological divergence of a monophyletic cichlid species pair under fully sympatric conditions in Lake Ejagham, Cameroon. Mol. Ecol. 10, 1471-1488.

Schliewen, U. K., Tautz, D. \& Pääbo, S. 1994 Sympatric speciation suggested by monophyly of crater lake cichlids. Nature 368, 629-632.

Schluter, D. 2000 The ecology of adaptive radiation, Oxford Series in Ecology and Evolution. New York: Oxford University Press.

Schneider, C. J. 1996 Distinguishing between primary and secondary intergradation among morphologically differentiated populations of Anolis marmoratus. Mol. Ecol. 5, 239-249.

Schoener, T. W. 1977 Competition and the niche. In Biology of the Reptilia vol. 7 (ed. C. Gans \& D. W. Tinkle), pp. 35136. New York: Academic.

Schwartz, A. \& Thomas, R. 1975 A check-list of West Indian amphibians and reptiles. Carnegie Mus. Nat. Hist. Spec. Publ. 1, 1-216.
Seehausen, O. \& van Alphen, J. M. 1999 Can sympatric speciation by disruptive sexual selection explain rapid evolution of cichlid diversity in Lake Victoria? Ecol. Lett. 2, 262-271.

Shaw, P. W., Turner, G. F., Idid, M. R., Robinson, R. L. \& Carvalho, G. R. 2000 Genetic population structure indicates sympatric speciation of Lake Malawi pelagic cichlids. Proc. R. Soc. Lond. B 267, 2273-2280. (doi:10.1098/ rspb.2000.1279)

Stafford, P. J. \& Meyer, J. R. 1999 A guide to the reptiles of Belize. New York: Academic.

Stenson, A. G., Malhotra, A. \& Thorpe, R. S. 2002 Population differentiation and nuclear gene flow in the Dominican anole (Anolis oculatus). Mol. Ecol. 11, 1679-1688.

Sturmbauer, C. \& Meyer, A. 1992 Genetic-divergence, speciation and morphological stasis in a lineage of African cichlid fishes. Nature 358, 578-581.

Sturmbauer, C., Baric, S., Salzburger, W., Ruber, L. \& Verheyen, E. 2001 Lake level fluctuations synchronize genetic divergences of cichlid fishes in African lakes. Mol. Biol. Evol. 18, 144-154.

Swofford, D. 2002 PAUP*. Phylogenetic analysis using parsimony ( ${ }^{*}$ and other methods). Sunderland, MA: Sinauer.

Tegelström, H. 1987 Transfer of mitochondrial DNA from the northern red-backed vole (Clethionomys rutilus) to the bank vole (C. glareolus). F. Mol. Evol. 24, 218-227.

Thomas, Y., Bethenod, M. T., Pelozuelo, L., Frerot, B. \& Bourguet, D. 2003 Genetic isolation between two sympatric host-plant races of the European corn borer, Ostrinia nubilalis Hubner. I. Sex pheromone, moth emergence timing, and parasitism. Evolution 57, 261-273.

Thorpe, R. S. \& Malhotra, A. 1996 Molecular and morphological evolution within small islands. Phil. Trans. R. Soc. Lond. B 351, 815-822.

Thorpe, R. S. \& Stenson, A. G. 2003 Phylogeny, paraphyly and ecological adaptation of the colour and pattern in the Anolis roquet complex on Martinique. Mol. Ecol. 12, 117-132.

Veith, M., Kosuch, J. \& Vences, M. 2003 Climatic oscillations triggered post-Messinian speciation of Western Palearctic brown frogs (Amphibia, Ranidae). Mol. Phylogenet. Evol. 26, 310-327.

Wiens, J. J. \& Penkrot, T. A. 2002 Delimiting species using DNA and morphologicical variation and discordant species limits in spiny lizards (Sceloporus). Syst. Biol. 51, 69-91.

As this paper exceeds the maximum length normally permitted, the authors have agreed to contribute to production costs.

Visit www.journals.royalsoc.ac.uk and navigate through to this article in Proceedings: Biological Sciences to see the accompanying electronic appendices. 